\title{
Ethical Considerations for the Conduct of Antidementia Trials in Canada
}

\author{
John D. Fisk
}

\begin{abstract}
Clinical trials in persons with dementia bring into focus the ethical dilemmas frequently confronting the clinician-scientist. Despite the existence of various ethical guidelines, most with common underlying principles, few are specific to dementia. A particular difficulty is finding a balance between respect for the autonomy of the individual and the protection of vulnerable persons, while at the same time defining an acceptable risk/benefit ratio for the study. The availability of symptomatic treatments for Alzheimer's disease also now make it difficult to argue that withholding treatment from those in the placebo arm of a clinical trial fulfills one's duty to provide best care. Those conducting clinical trials must be knowledgeable about existing legislation and ethical guidelines in order to justify to themselves and others, the design of clinical trials and their risks. They must be prepared to educate patients and family members about dementia and research, determine each potential subject's competence to consent, and ensure that decisions about participation are in accordance with the best interests of the subject. Ethical conduct of clinical trials of new antidementia therapies will require that everyone involved understands the values and beliefs that guide their decision-making and the potentially conflicting roles facing the clinician-scientist.
\end{abstract}

RÉSUMÉ: Considérations éthiques concernant le déroulement des essais cliniques sur la démence au Canada. Les essais cliniques chez les sujets déments illustrent les dilemmes éthiques auxquels le clinicien-chercheur est fréquemment confronté. Malgré l'existence de différentes lignes directrices en éthique, la plupart ayant des principes sous-jacents communs, peu sont spécifiques de la démence. Il est particulièrement difficile d'établir un équilibre entre le respect de l'autonomie de l'individu et la protection des personnes vulnérables tout en définissant un taux de risques/bénéfices acceptable pour l'étude. Il est devenu difficile de soutenir que le fait de ne pas traiter les sujets du groupe placebo est compatible avec le devoir de leur procurer les meilleurs soins possibles vu la disponibilité de traitements symptomatiques pour la maladie d'Alzheimer. Ceux qui effectuent des essais cliniques doivent connaître la législation et les lignes directrices éthiques afin de se justifier et de justifier vis-à-vis des autres le plan des essais cliniques et les risques qui y sont associés. Ils doivent être prêts à informer les patients et les membres de leur famille sur la démence et la recherche, à déterminer la compétence de chaque sujet potentiel à donner son consentement et à assurer que les décisions au sujet de la participation sont dans le meilleur intérêt du sujet. Il faudra que toutes les personnes impliquées comprennent les valeurs et les croyances qui guident la prise de décision et les rôles conflictuels potentiels auxquels fait face le clinicien-chercheur pour un déroulement éthique des essais cliniques sur les nouveaux médicaments antidémence.

Can. J. Neurol. Sci. 2007; 34: Suppl. 1 - S32-36

Clinical research creates tension between the roles of clinician and scientist that must be acknowledged. While attempts have been made to draw distinctions between the ethics of clinical care and the ethics of research, ${ }^{1}$ such distinctions have been strongly criticized and are inconsistent with most consensus guidelines. ${ }^{2-4}$ Distinctions between the roles of clinician and scientist do exist, however, and the difference between managing an individual's health and conducting a clinical trial must be clear to both the research participant and the clinician-scientist. Clinicians also need to make informed decisions about their participation in research and to do so, must be aware of the ethical issues that they are likely to face when they conduct a

\footnotetext{
From the Departments of Psychiatry, Medicine and Psychology, Dalhousie University, Halifax, Nova Scotia, Canada.

ReCEIVEd October 31, 2005. ACCEPTED In FinAl FORM MAY 1, 2006. Reprint requests to: John D. Fisk, A.J. Lane Memorial Building, 5909 Veteran's Memorial Lane, Halifax, Nova Scotia, B3H 2E2, Canada.
} 
clinical trial. ${ }^{5,6}$ Research on Alzheimer's disease (AD) and other dementias presents particular challenges, although none of the specific ethical issues are themselves unique to dementia.

The principles that best describe ethical decision-making in the clinical trial context were articulated in the "Belmont Report," produced by the U.S. National Commission for the Protection of Human subjects of Biomedical and Behavioural Research. ${ }^{7}$ These principles include: respect for persons, beneficence (i.e., the obligation to do no harm and to maximize the potential for benefit while minimizing the potential for harm), and justice. Their application to clinical trials involves assessment of risks and benefits, appropriate selection of subjects, and informed consent. Differences in culture and legislation may influence how this is done, but the principles remain central to most research ethics guidelines, such as the World Medical Association's Declaration of Helsinki, ${ }^{3}$ the Ethical Guidelines for Biomedical Research of the Council for International Organizations of Medical Sciences, ${ }^{4}$ the Council of Europe's Convention on Human Rights and Biomedicine, ${ }^{8}$ and Canada's Tri-Council Policy Statement: Ethical Conduct for Research Involving Humans (TCPS). ${ }^{9}$ All are only guidelines, however, and finding the correct balance of these principles in a specific research context may be difficult.

While the existence of various ethical guidelines with common underlying principles should help resolve difficult issues, few of the guidelines have specific recommendations regarding dementia. Moreover, a patchwork approach to research ethics governance coupled with the use of different guidelines in different contexts can increase the difficulties for the individual clinician-scientist considering embarking on a clinical trial. In Canada, research on human subjects conducted at institutions that receive federal funding must be conducted in accordance with the TCPS, which was established jointly by the Canadian Institutes for Health Research (CIHR), the Social Sciences and Humanities Research Council, and the National Science and Engineering Research Council. ${ }^{9}$ Research conducted outside such institutions, however, is largely governed by voluntary industry guidelines, primarily the International Committee on Harmonization - Good Clinical Practice guidelines (ICH-E6). ${ }^{10}$ The situation is similar in the United States where most research is conducted in accordance with federal regulations known as the "common rule," 11 while privately sponsored research outside the jurisdiction of the Food and Drug Administration does not require adherence to these regulations. ${ }^{12}$

Ethical principles that are particularly difficult to balance in clinical trials for dementia are respect for the autonomy of the individual and the protection of vulnerable persons. The TCPS states that "the principle of respect for human dignity entails high ethical obligations to vulnerable populations" (Article 2.9), ${ }^{9}$ and while it is generally accepted that "protection should be proportionate to the risk involved, with the least protection required when research involves minimal risk," 13 a precise definition of "minimal risk" has been elusive. ${ }^{14}$

While finding an acceptable risk/benefit ratio is central to the evaluation of all clinical trials, ${ }^{14}$ it is particularly difficult for studies of dementia because of uncertainty about subjects' capacity for autonomous informed decision-making. As noted over a decade ago by High and colleagues: 15 "no clear consensus exists either in the literature or in regulatory guidelines as to what constitutes an acceptable degree of risk when cognitively impaired persons are involved in research." It has been argued that research with cognitively impaired individuals is acceptable if it does not involve a "risk of harm beyond a minor increment over minimal," 16 but such vague descriptions have meant that resolution of this difficult issue has been left to individual researchers and their local research ethics boards.

The currently available approved treatments for dementia in Canada remain limited to symptomatic treatments for AD. The efficacy of cholinesterase inhibitors in clinical trials for AD has been consistently demonstrated, ${ }^{17}$ and there is some evidence of efficacy for vascular cognitive impairment, ${ }^{18,19}$ Parkinson's disease with dementia ${ }^{20}$ and Lewy Body dementia. ${ }^{21}$ However, even for $\mathrm{AD}$, scepticism and debate surrounds the use of these symptomatic treatments since: "it is not possible to identify those who will respond to treatment", ${ }^{17}$ and "the treatment effects are small and not always apparent in practice". ${ }^{22}$ Therapies aimed at modifying the underlying disease processes will be developed but, as we have already seen, these therapeutic advances will carry with them increased risks and/or increased uncertainty about the risks, in addition to their increased promise of effective treatment. ${ }^{23}$ This adds to the complexity of decision-making both for the potential investigator and for the potential research subject.

A diagnosis of dementia or other forms of cognitive impairment does not preclude competence to provide informed consent for participation in clinical trials ${ }^{24}$ or in non-therapeutic research, which contains minimal risk. In part, this reflects improved diagnostic methods which allow $\mathrm{AD}$ and other dementias to be detected at earlier stages in which many cognitive and functional abilities are relatively preserved. The conceptualization of Mild Cognitive Impairment ${ }^{25}$ as a diagnostic entity that warrants clinical therapeutic and prevention trials reinforces this trend. Regardless, an individual's competence to consent to either treatment or research participation is not simply a matter of the stage of dementia or severity of cognitive impairment for that individual.

Formal competency assessment methodologies can be complex and time-consuming and it would be advantageous if standard mental status screening instruments could be used to determine consent capacity as well as for diagnostic screening purposes. However, while there is some evidence that screening instruments can provide guidance as to the probability of competency to consent to treatment, ${ }^{26,27}$ and to research, ${ }^{28}$ the complexity of the issues precludes any simple means of establishing competency in a specific treatment or research setting with certainty. ${ }^{29}$ The use of standardized methods to determine competency to provide informed consent for treatment has been promoted by some but there remains no clear consensus on the best standardized assessment methods to address this. ${ }^{30,31}$ Moreover, given the inconsistencies in expert clinical judgments on the issue of competence for mildly affected patients, ${ }^{32}$ the question can be raised as to what can be considered a 'gold standard' for evaluating such methods. Research on competency for the provision of informed consent in a research context has been less common than for consent to treatment. While Kim and colleagues ${ }^{33}$ have reported that even mild AD has significant effects on competency to consent to research, this issue remains an important topic for further research. Even if practical standardized assessments of competency to participate in clinical 
or research decision making were to become available, social, cultural and legislative variations are still likely to limit their application.

Competence is not a uniform construct and one can be competent in some aspects of one's life (e.g., consenting to research), without being competent in others (e.g., driving a motor vehicle). ${ }^{30}$ This concept of a 'sliding-scale' of competency, ${ }^{34}$ is acknowledged in the TCPS statement: "Competence to participate in research, then, is not an all-ornothing decision. It requires that they be competent to make an informed decision about participation in particular research. Competence is neither a global condition nor a static one; it may be temporary or permanent" (Article 2.9). ${ }^{9}$ Changes in competency are to be expected in studies of dementia, and there is a clear need for ongoing monitoring and reaffirmation of consent/assent. Thus, even in the absence of "gold standard" methods, research ethics boards should still expect that clinical trial protocols will provide a description of how the ability of potential subjects to understand the nature of the research, the consequences of participation (i.e., potential risks and benefits), and alternative choices will be determined and monitored. ${ }^{35,36}$ It is important to recognize that most published ethical guidelines take a relatively protectionist stance with regard to avoiding potential exploitation of individuals who are not competent enough to provide informed consent. ${ }^{37}$ In contrast, persons affected by medical conditions and their advocates generally place greater emphasis on ensuring that specific groups are not denied the potential to benefit from participation in research. An example of this relatively inclusive stance is articulated in the statement by High and colleagues: ${ }^{15}$ "To deny persons access to research participation out of fear of exploitation of specific groups of persons is to avoid rather than accept and practice ethical responsibility," and this position has been adopted in the ethical guidelines of the Alzheimer Society of Canada. ${ }^{35}$

Across North America, the absence of clear and consistent legislation regarding competency to participate in research for cognitively impaired persons presents well-recognized difficulties. ${ }^{38,39}$ Consequently, researchers often rely on family members of persons with dementia to provide "third party authorization," even when there has been no legal determination that the potential research subject lacks competence to provide informed consent. Advance directives for research participation could help to ensure that proxy decisions reflect the prior attitudes and values of the research subject, but their use is not without controversy, ${ }^{16,40,41}$ and they are rarely available. Reliance on proxies to provide informed consent for their family members' participation in research requires that the proxy be well informed about dementia. However, studies of caregiver knowledge about $\mathrm{AD}$ have typically reported relatively poor understanding of such issues as causes, symptoms and treatments, ${ }^{42}$ all of which are important when considering participation in trials of new therapies. As more is learned about dementias and more new potential therapies become available, decision-making on the part of patients and their families will become increasingly complex and there is a clear need to ensure that patients and their families have adequate education about dementia before suggesting research participation.

The need to develop effective therapies in the later stages of dementia will ensure that proxy decision-making for consent to participate in research remains an important ethical issue.
Although we may be reassured by reports that proxies typically involve the potential research subject in the decision-making process, ${ }^{43,44}$ the process of providing proxy consent can itself be burdensome, ${ }^{44}$ and proxies do not always feel that their decisions are consistent with the research subject's desires. ${ }^{43}$ Moreover, the social situation of the caregiver who is expected to serve as a proxy, and their relation to the affected individual, may influence the caregiver's tolerance for risk to the prospective research subject. ${ }^{45}$ Those involved in clinical trials must understand that the interests of persons with dementia and their proxy decisionmakers may differ. Clinician-scientists have an obligation to determine, to the best of their ability, that the decision to participate in a clinical trial has been guided by the individual's wishes and/or that it has been made with the individual's best interests in mind. ${ }^{10,15,36}$

The development and approval of symptomatic treatments for $\mathrm{AD}$ in Canada has now brought the issue of placebo controls in clinical trials of antidementia therapies to the forefront. The availability of these treatments makes it difficult to argue that withholding them from persons with AD enrolled in the placebo arm is ethically acceptable, ${ }^{46}$ and that placebo-controlled trials for new $\mathrm{AD}$ therapies fulfill the clinician-scientist's duty to provide best care. ${ }^{47}$ The use of placebos in medicine and in research has a long and complex history, ${ }^{48}$ and the legal, ethical and scientific issues of placebo use are equally complex. ${ }^{49}$ The lack of consistency in the existing ethical guidelines on the use of placebos in clinical trials led Health Canada and the Canadian Institutes of Health Research to launch a National Placebo Initiative in the fall of 2001. The goals of this initiative were to clarify and harmonize Health Canada's regulatory approach, which is based on the ICH-E10 Guidelines, 50 and CIHR's TCPS. ${ }^{9}$ The final report of the National Placebo Working Committee recommends: "as a general rule, research subjects in the control group of a trial of a diagnostic, therapeutic or preventative intervention should receive an established effective therapy." 51 While this statement appears to negate the possibility of placebo controls in antidementia trials for $\mathrm{AD}$, the existence of established effective symptomatic treatments for AD does not preclude the design of ethically acceptable placebo-controlled trials of new antidementia therapies. For situations in which no established effective therapy exists (as is currently the case for most dementias other than AD), a placebo-controlled trial is both ethically acceptable and scientifically preferred. Other situations in which placebo controls are acceptable include: add-on trials to existing therapies, studies of patients known to be refractory to treatment, studies of patients who have previously stopped treatments due to unsatisfactory response, and studies of patients who have made an informed refusal of existing therapies. ${ }^{51}$ In addition, placebo-controlled trials are appropriate when new evidence raises doubts about the benefits of existing therapies and challenges their claim as "established effective therapy." Such is likely to occur more frequently as the expectations for post-marketing surveillance of new and costly therapies increase. While the recommendations of the National Placebo Working Committee may help deal with this difficult ethical issue, they remain guidelines that require consideration and application to each specific circumstance.

In caring for persons with $\mathrm{AD}$ and other dementias, ethical dilemmas are all too frequent. Clinical trials, however, present 
situations that bring these issues into focus. Clinician-scientists who choose to engage in clinical trials research should do so in an informed manner. ${ }^{6}$ They must recognize that they will be expected to justify to themselves and others, on the basis of existing legislation and ethical guidelines, the design of the clinical trial and its risks and benefits. They must be prepared to educate patients and family members about dementia, as well as about clinical research, ${ }^{52}$ and to determine the potential subject's competency to consent. They must be prepared to deal with any real or potentially perceived conflicts of interest ${ }^{53}$ and to inform potential research subjects about these. ${ }^{54}$ They must also ensure that the decisions about research participation, whether by the patient or their family members, are made in accordance with the best interests of the subject. When one considers clinical trials of new antidementia therapies, it is critical that everyone involved understands the values and beliefs on which their decisionmaking is based. Understanding one's potentially conflicting roles is critical for ethical decision-making on the part of clinician-scientists who are engaged in clinical trials of new antidementia therapies.

\section{REFERENCES}

1. Miller FG, Brody $\mathrm{H}$. What makes placebo-controlled trials unethical? Am J Bioethics. 2002; 2: 3-9.

2. Lemmens T, Miller PB. Avoiding a Jekyll-and-Hyde approach to the ethics of clinical research and practice. Am J Bioethics. 2002; 2: 14-7.

3. World Medical Association, World Medical Association Declaration of Helsinki, Ethical Principles for Medical Research Involving Human Subjects. Adopted 1964, last amended 2002, [cited April 13, 2006]. Available from: http://www.wma.net/e/policy/b3.htm.

4. Council for International Organizations of Medical Sciences. (2002). International Ethical Guidelines for Biomedical Research Involving Human Subjects. [cited April 13, 2006]. Available from: http://www.cioms.ch/frame_guidelines_nov_2002.htm.

5. Graham C, Holmes C, Lindesay J. Clinical involvement in antidementia drug trials - why bother? Int J Geriatric Psychiatry. 1999; 14: 258-60.

6. Lader EW, Cannon CP, Ohman EM, Newby LK, Sulmasy DP, Barst $\mathrm{R}$, et al. The clinician as investigator: participating in clinical trials in the practice setting. Circulation. 2004; 109: 2672-9.

7. National Commission for the Protection of Human Subjects of Biomedical and Behavioural Research, The Belmont Report, Ethical Principles and Guidelines for the Protection of Human Subjects of Research, 1979, [cited April 13, 2006]. Available

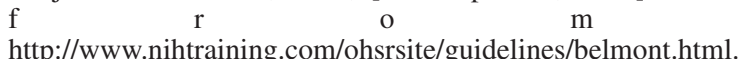

8. Council of Europe, Convention for the Protection of Human Rights and Dignity of the Human Being with regard to the Application of Biology and Medicine: Convention on Human Rights and Biomedicine, Oviedo, 4.IV.1997. [cited April 13, 2006], Available from: http://conventions.coe.int/Treaty/en/Treaties/ Html/164.htm.

9. Tri-Council Policy Statement: Ethical Conduct for Research Involving Humans, 1998 (with 2000, 2002 updates), [cited April 13, 2006]. Available from: http://pre.ethics.gc.ca/english/policystatement/ policystatement.cfm.

10. International Conference on Harmonization of Technical requirements for Registration of Pharmaceuticals for Human Use. (2004). Good Clinical Practice: Consolidated Guidelines E6. [cited April 13, 2006]. Available from: http://www.ich.org/cache/ compo/276-254-1.html.

11. Department of Health and Human Services. (2001). Code of Federal Regulations Title 45 Part 46 Regulations for the Protection of Human Subjects, Section 46.102.i, [cited April 13, 2006]. Available from: http://www.hhs.gov/ohrp/humansubjects/ guidance $/ 45 \mathrm{cfr} 46 . \mathrm{htm}$.
12. Steinbrook R. Improving protection for research subjects. N Eng J Med. 2002; 346: 1425-30.

13. Office of Human Subjects Research, Information Sheet 7, National Institutes of Health, [cited April 13, 2006]. Available from: http://ohsr.od.nih.gov/info/sheet3.html.

14. Weijer C. The ethical analysis of risk. J Law Med Ethics 2000; 28 : 344-61.

15. High DM, Whitehouse PJ, Post SG, Berg L. Guidelines for addressing ethical and legal issues in Alzheimer disease research: a position paper. Alzheimer Dis Assoc Disord 1994; 8: 66-74.

16. Keyserlingk EW, Glass K, Kogan S, Gauthier S. Proposed guidelines for the participation of persons with dementia as research subjects. Perspect Biol Med 1995; 38: 319-62.

17. Birks J. Cholinesterase inhibitors for Alzheimer's disease. The Cochrane Database of Systematic Reviews 2006, Issue 1. Art. No.: CD005593. DOI: 10.1002/14651858.CD005593.

18. Craig D, Birks J. Rivastigmine for vascular cognitive impairment. The Cochrane Database of Systematic Reviews 2004, Issue 2. Art. No.: CD004744. DOI: 10.1002/14651858.CD004744.pub2.

19. Malouf R, Birks J. Donepezil for vascular cognitive impairment. The Cochrane Database of Systematic Reviews 2004, Issue 1. Art. No.: CD004395. DOI: 10.1002/14651858.CD004395.pub2.

20. Maidment I, Fox C, Boustani M. Cholinesterase inhibitors for Parkinson's disease dementia. The Cochrane Database of Systematic Reviews 2006, Issue 1. Art. No.: CD004747. DOI: 10.1002/14651858.CD004747.pub2.

21. Wild R, Pettit T, Burns A. Cholinesterase inhibitors for dementia with Lewy bodies. The Cochrane Database of Systematic Reviews 2003, Issue 3. Art. No.: CD003672. DOI:10.1002/ 14651858.CD003672.

22. Birks J, Harvey RJ. Donepezil for dementia due to Alzheimer's disease. The Cochrane Database of Systematic Reviews 2006, Issue 1. Art. No.: CD001190. DOI: 10.1002/14651858 .CD001190.pub2.

23. Greenberg SM, Bacskai BJ, Hyman BT. Alzheimer disease's double-edged vaccine. Nature Med. 2003; 9: 389-90.

24. Karlawish JHT, Casarett DJ, James BD. Alzheimer's disease patients' and caregivers' capacity, competency, and reasons to enroll in an early-phase Alzheimer's disease clinical trial. J Am Geriatr Soc. 2002; 50: 2019-24.

25. Petersen RC, Stevens JC, Ganguli M, Tangalos EG, Cummigs JL, DeKosky ST. Practice parameter: Early detection of dementia: mild cognitive impairment (an evidence-based review). Neurology. 2001; 56: 1133-42.

26. Etchells E, Darzins P, Silberfeld, M, Singer PA, McKenny J, Naglie $\mathrm{G}$, et al. Assessment of patient capacity to consent to treatment. J Gen Intern Med. 1999; 14: 27-34.

27. Karlawish JHT, Casarett DJ, James BD, Xie SX, Kim SYH. The ability of persons with Alzheimer's disease (AD) to make a decision about taking an $\mathrm{AD}$ treatment. Neurology. 2005; 64: 1514-9.

28. Kim SYH, Caine ED. Utility and limits of the Mini Mental State Examination in evaluating consent capacity in Alzheimer's disease. Psychiatr Serv. 2002; 53: 1322-4.

29. McQuillan MP, Tariot P. Who can say yes (or no) to a physician and how does the physician know they can? Neurology. 2005; 64: 1494-5.

30. Marson DC. Loss of competency in Alzheimer's disease: conceptual and psychometric approaches. Int J Law Ethics. 2001; 24: 267-83.

31. Moye J, Karel MJ, Azar AR, Gurrera RJ. Capacity to consent to treatment: Empirical comparison of the instruments in older adults with and without dementia. Gerontologist. 2004; 44: 166-75.

32. Marson DC, McInturff B, Hawkins L, Bartolucci A, Harrell LE. Consistency of physician judgements of capacity to consent in Alzheimer's disease. J Am Geriatr Soc. 1997; 45: 453-7.

33. Kim SY, Caine ED, Currier GW, Leibovici A, Ryan JM. Assessing the competence of persons with Alzheimer's disease in providing informed consent for participation in research. Am J Psychiatry. 2001; 158: 712-7. 
34. High DM. Research with Alzheimer's disease subjects: informed consent and proxy decision-making. J Am Geriatr Soc. 1992; 40: 950-7.

35. Fisk JD, Sadovnick AD, Cohen CA, Gauthier S, Dossetor, J, Eberhart A, et al. Ethical guidelines of the Alzheimer Society of Canada. Can J Neurol Sci. 1998; 25: 242-8.

36. Karlawish JHT. Research involving cognitively impaired adults. N Engl J Med. 2003; 348: 1389-92.

37. Wendler D, Prasad K. Core safe guards for clinical research with adults who are unable to consent. Ann Intern Med. 2001; 135: 514-23.

38. Alzheimer Society of Canada. Ethical Guidelines, 2003. [cited April 13, 2006]. Available from: http://www.alzheimer.ca/english/care/ ethics-intro.htm.

39. The Ethics and Humanities Subcommittees of the American Academy of Neurology. Ethical issues in clinical research in neurology: advancing knowledge and protecting human research subjects. Neurology. 1998; 50: 592-5.

40. Sachs GA, Stocking CB, Stern R, Cox DM, Hougham G, Sachs RS. Ethical aspects of dementia research: informed consent and proxy consent. Clin Res. 1994; 42: 403-12.

41. Candilis PJ, Wesley RW, Wichman A. A survey of researchers using a consent policy for cognitively impaired human research subjects. IRB. 1993; 15: 1-4.

42. Werner P. Correlates of family caregivers knowledge about Alzheimer's disease. Int J Geriatr Psychiatry. 2001; 16: 32-8.

43. Karlawish JH, Casarett D, Klocinski J, Sankar P. How do AD patients and their caregivers decide whether to enroll in a clinical trial? Neurology. 2001; 56: 789-92.

44. Sugarman J, Cain C, Wallace R, Welsh-Bohmer KA. How proxies make decisions about research for patients with Alzheimer's disease. J Am Geriatr Soc. 2001; 49: 1110-9.

45. Karlawish JH, Klocinski JL, Merz J, Clark CM, Asch DA. Caregivers' preferences for the treatment of patients with Alzheimer's disease. Neurology. 2000; 55: 1008-14.
46. Huston P, Peterson R. Withholding proven treatment in clinical research. N Engl J Med. 2001; 345: 912-4.

47. Freedman B, Glass K, Weijer C. Placebo orthodoxy in clinical research. II: ethical, legal, and regulatory myths. J Law Med Ethics. 1996; 24: 252-9.

48. Shapiro E, Shapiro A. The powerful placebo: from ancient priest to modern physician. Baltimore: The John Hopkins University Press; 1997.

49. Guess HA, Kleinman A, Kusek JW, Engel LW, editors. The science of the placebo. London: BMJ Books; 2002.

50. International Conference on Harmonization of Technical requirements for Registration of Pharmaceuticals for Human Use. (2000) Choice of Control Group and Related Issues in Clinical Trials E10. [cited April 13, 2006]. Available from: http://www.ich.org/cache/compo/276-254-1.html.

51. National Placebo Initiative, Final Report of the National Placebo Working Committee on the Appropriate use of Placebos in Clinical Trials in Canada, July 2004, [cited April 13, 2006]. Available from: http://www.cihr-irsc.gc.ca/e/25139.html.

52. Chen DT, Miller FG, Rosenstein DL. Clinical research and the physician-patient relationship. Ann Intern Med. 2003; 138: 669-72.

53. Morin K, Rakatansky H, Riddick FA. Managing conflict of interest in the conduct of clinical trials. JAMA. 2002; 287:78-84.

54. Kim SYH, Millard RW, Nisbet P, Cox C, Caine ED. Potential research participants' views regarding researcher and institutional financial conflicts of interest. J Med Ethics. 2004; 30:73-9. 